\title{
PROGRAMAS DE DESENVOLVIMENTO COMPORTAMENTAL: INFLUÊNCIAS SOBRE OS OBJETIVOS ESTRATÉGICOS
}

BEHAVIORAL DEVELOPMENT PROGRAMS: INFLUENCES ON STRATEGIC GOALS

\section{RESUMO}

A pesquisa analisa a relação entre programas de desenvolvimento comportamental aplicados à área comercial e a efetivação dos objetivos estratégicos da organização. A pesquisa teórica fundamenta-se em referenciais da gestão estratégica de pessoas, treinamento e desenvolvimento e avaliação dos resultados de programas de treinamento e desenvolvimento. A pesquisa é baseada em estudo de caso realizado na Rede Independência de Comunicação (RIC). O tratamento dos dados envolveu técnicas estatísticas de análise de regressão linear simples e estatística univariada. Os resultados mostram que os investimentos em programas de desenvolvimento comportamental e os objetivos estratégicos da organização têm relação positiva e significante.

\section{Amir El-Kouba}

Professor da Escola de Negócios, Pontifícia Universidade Católica do Paraná - PR, Brasil

amir@vencendodesafios.com.br

\section{Karina De Déa Roglio}

Professora do Programa de Pós-Graduação em Administração, Pontifícia Universidade Católica do Paraná - PR, Brasil

karina.roglio@pucpr.br

\section{Jansen Maia Del Corso}

Professor do Programa de Pós-Graduação em Administração, Pontifícia Universidade Católica do Paraná - PR, Brasil del.corso@pucpr.br

\section{Wesley Vieira da Silva}

Professor do Programa de Pós-Graduação em Administração, Pontifícia Universidade Católica do Paraná - PR, Brasil wesley.vieira@pucpr.br

Recebido em 02.04.2008. Aprovado em 29.05.2009

Avaliado pelo sistema double blind review

Editor Científico: Sandro Márcio da Silva

\begin{abstract}
This research analyzes the relationship between behavioral development programs of commercial areas and the attainment of organization strategic goals. The theoretical research is based on people strategic management references, training and development, and assessment of training and development programs results. The research is based on a case study at Rede Independência de Comunicação (RIC). Data handling involved simple linear regressions and univaried statistical analysis. Results show that the investments in behavioral development programs and the organization strategic goals have a positive and significant relation.
\end{abstract}

PALAVRAS-CHAVE Comportamento organizacional, desenvolvimento comportamental, objetivos estratégicos, resultados organizacionais, programas de treinamento.

KEYWORDS Organizational behavior, behavioral development, strategic goals, organization results, behavioral training programs. 


\section{INTRODUÇÃo}

A informação e o conhecimento são fatores determinantes para que uma organização possa agregar valor à sua marca e aos seus produtos e serviços, bem como para ajustar seus processos visando a conquistar a fidelidade dos clientes e avançar sobre novos mercados. Nesse contexto, as diferentes áreas da organização dependem das características ambientais, do negócio, da cultura, das funções e processos, entre outras variáveis. Segundo Rocha-Pinto e outros (2003), o alinhamento dessas variáveis à estratégia da organização e o sentido de unidade de integração de todas as áreas funcionais devem ser considerados primordiais. As áreas de Gestão de Recursos Humanos (RH) e Comercial, que constituem o foco desta pesquisa, não fogem a essa premissa.

A área Comercial busca uma valorização da imagem da organização e dos seus produtos no mercado, assim como direcionar os processos e ações para a melhoria do desempenho organizacional no que diz respeito às vendas e à lucratividade. A área de Recursos Humanos, por sua vez, enfrenta o desafio de alinhar suas políticas às estratégias empresariais. Esse alinhamento requer uma integração entre as diversas práticas de recursos humanos e o foco em criar competências individuais e capacidades organizacionais substancialmente melhores do que aquelas dos concorrentes (ULRICH; BROCKBANK, 2005).

Dentre as práticas de Gestão de Recursos Humanos que estimulam o desenvolvimento das competências individuais destacam-se os programas de desenvolvimento comportamental, que têm como principal objetivo fomentar o comprometimento das pessoas com o alcance dos objetivos estratégicos da organização.

Uma das características desses programas é que a avaliação da sua eficácia apresenta um forte apelo à subjetividade. Para Feuillette (1991), a avaliação garante que o esforço despendido em matéria de tempo, energia e dinheiro ofereça à empresa um retorno significativo, que pode ocorrer de diferentes maneiras: maior comprometimento e profissionalismo, revigoramento da motivação e comunicação mais eficaz, que promovem a melhoria da rentabilidade e da produtividade a curto, médio e longo prazos.

Este artigo é baseado em um estudo que analisa as influências de programas de desenvolvimento comportamental sobre os resultados organizacionais sob uma perspectiva quantitativa. Visa, com isso, a contribuir para a redução do nível de subjetividade na mensuração dos seus resultados.

Para atender ao objetivo definido, o artigo está organizado da seguinte forma: a revisão de literatura tem como foco o tema Gestão Estratégica de Recursos Humanos, com atenção especial ao desenvolvimento estratégico de pessoas, avaliação de programas de treinamento e desenvolvimento e programas de desenvolvimento comportamental. Em seguida, são apresentados a metodologia utilizada na pesquisa empírica e os resultados obtidos. Por fim, são desenvolvidas as considerações finais.

\section{GESTÃO ESTRATÉGICA DE RECURSOS HUMANOS}

Apesar das diferenças de enfoque, a maioria das teorias sobre administração estratégica atribui elevado grau de importância ao papel das pessoas e dos grupos na implementação das estratégias organizacionais.

Para Saraiva e Carrieri (2007, p. 5), o contexto da estratégia pode ser visto como o conjunto de variáveis, tais como o tempo, a cultura organizacional, o ambiente, o nível de estabilidade ou mutabilidade, as atividades, a estrutura, a tecnologia e, ainda, a liderança e o sistema político interno.

A compreensão dos recursos humanos como uma fonte de vantagem competitiva sustentável para as organizações é contemplada na visão baseada em recursos (Resource based view - RBV). A idéia central desta visão é explicar a criação, manutenção e renovação da vantagem competitiva em termos dos recursos internos à organização (BARNEY, 1991). De acordo com Kretzer (2002), esta abordagem considera as competências, capacidades e habilidades como sendo as bases do conhecimento produtivo e organizacional e, por sua vez, a mais importante fonte de vantagem competitiva.

Wright, Dunford e Snell (2001) apontam pesquisas que fortalecem essa compreensão e que definem o conhecimento (ARGOTE; INGRAM, 2000; GRANT, 1996; LEIBESKIND, 1996), a potencialidade dinâmica (EISENHARDT; MARTIN, 2000; TEECE; PISANO; SCHUEN, 1997), as organizações em aprendizagem (FIOL; LYLES, 1985; FISHER; WHITE, 2000) e a liderança (FINKELSTEIN; HAMBRICK, 1996; NORBURN; BIRLEY, 1988; THOMAS, 1988) como fontes de vantagem competitiva que interligam a estratégia da empresa e seus recursos humanos.

A aceitação crescente de recursos internos como fonte de vantagem competitiva trouxe legitimidade à afirmação de que as pessoas são estrategicamente importantes para o sucesso na implementação de estratégias. Com essa ênfase, a popularidade da RBV na literatura relativa à Gestão Estratégica de Recursos Humanos não foi surpreendente, conforme comprovam estudos de Capelli e Singh (1992), Wright e outros (1994), Lado e Wilson (1994), Huselid 
(1995), Boxall (1996), Lepak e Snell (1999) e Richard (2001).

De acordo com Barney e Wright (1998, p. 32-37), para avaliar o valor dos recursos humanos para a organização, assim como a efetividade da função de RH no gerenciamento desses recursos para gerar vantagem competitiva sustentável, é necessário analisar quatro atributos: os recursos devem ser a) valiosos, no sentido de explorar as oportunidades e/ou neutralizar as ameaças, b) raros, c) difíceis de imitar e d) organizados por meio de sistemas e práticas que possibilitem explorar as vantagens potenciais da integração vertical e horizontal das funções de RH.

March e Simon (1958, apud WRIGHT; DUNFORD; SNELL, 2001) alertam, no entanto, que a vantagem competitiva somente será criada se houver, por parte dos componentes da equipe, a decisão de contribuir. E essa decisão deverá, obrigatoriamente, ser uma escolha individual. Apenas com cada pessoa tomando a decisão de, coletivamente, acoplar seu comportamento às condições que beneficiam a empresa é que será possível a efetivação dos objetivos estratégicos da organização. Wright, Dunford e Snell (2001) registram que a RBV destaca esses interesses comuns e fornece a estrutura para o desenvolvimento do esforço colaborativo, favorecendo o comprometimento das pessoas com os objetivos estratégicos da organização.

Para Allen e Meyer (1996, 2000), o comprometimento organizacional é o estado psicológico que caracteriza a ligação do indivíduo à organização, tendo implicações na sua decisão de nela continuar. Segundo Rego, Cunha e Souto (2007, p. 7), a maior parte dos estudos sobre esse tema focaliza-se em três componentes: a orientação afetiva para com a organização (ligação afetiva); o reconhecimento dos custos associados com a saída da mesma (ligação instrumental); e um sentido de obrigação moral de nela permanecer (laço normativo).

Em função desses aspectos, a área de RH tende a desenvolver estratégias que permitam aos gestores e às equipes de trabalho maior compreensão dos seus papéis dentro da organização. Por meio de programas de desenvolvimento de competências, fortalecimento de equipes, acompanhamento e avaliação de desempenho, entre outros processos, busca subsidiar as pessoas para um efetivo comprometimento com os objetivos estratégicos da organização.

O grande desafio para a área de Gestão de Pessoas nas últimas décadas, segundo Paschini (2006), tem sido o alinhamento de três pilares: (1) a compreensão da estratégia da empresa; (2) o gerenciamento de uma cultura organizacional que dê sustentabilidade a essa estratégia; (3) a definição de políticas e ferramentas de gestão de pessoas que atuem como reforçadores da cultura desejada e da consecução da estratégia do negócio.

Para Cohen (1999), o modelo genérico de Administração Estratégica de Pessoas envolve: a) seleção estratégica de pessoal; b) avaliação estratégica de pessoal; c) recompensa estratégica de pessoal; d) desenvolvimento estratégico de pessoal.

\section{Desenvolvimento estratégico de pessoas}

A área responsável pelo desenvolvimento de pessoas é relativamente recente na arquitetura organizacional. Durante grande parte do século XX, o treinamento e desenvolvimento era percebido, segundo Oliveira (2006), como um conjunto de atividades de ensino profissional suplementar aplicado para adequar os trabalhadores às suas funções. A presença dessa área nas empresas decorreu da percepção de que o ensino formal era incapaz de formar qualitativa e quantitativamente os profissionais para ocupar cargos oferecidos pelo mercado de trabalho.

Na década de 1990, a área de Treinamento e Desenvolvimento trabalhava com uma metodologia que Moggi (2006) denominou "T\&D do tipo fast-food". Segundo análise do autor, era bastante comum a pretensão de desenvolver grandes contingentes de pessoas em curto espaço de tempo. Contudo, a partir dos resultados desses programas, conclui-se que os processos de desenvolvimento precisam ser customizados para cada realidade, a fim de atender às necessidades de cada cultura em particular.

De acordo com Pacheco e outros (2005), os treinamentos são convenientes na medida em que acrescentam valor aos processos e atendem aos objetivos específicos da organização. Com o surgimento de novas tecnologias e da globalização, apareceram outras necessidades de desempenho, que incluem inovação, agilidade e transformação da aprendizagem em vantagem competitiva.

Em ambientes que mudam rapidamente, as qualificações se tornam obsoletas com grande velocidade (COHEN, 1999). Por isso, o desenvolvimento de pessoas possui caráter estratégico nas organizações pretensamente competitivas. Conforme Milioni (2004), ações de treinamento devem buscar soluções criativas e permanentes frente ao seu valor estratégico.

Programas de desenvolvimento comportamental direcionados aos gestores que administram equipes e estratégias têm sido desenvolvidos com o intuito de minimizar os impactos da mudança.

Alguns tipos de treinamentos - especialmente os fora das empresas - e outros eventos corporativos podem fun- 
cionar como ritos importantes para combater as resistências às mudanças através da estimulação à cooperação, ao espírito de equipe e à obtenção de compromissos do grupo. A conquista do comprometimento das pessoas seria, nesse caso, fruto da compreensão da cultura e dos seus elementos em prol do fortalecimento das relações e da formação (ou reformulação) de uma identidade alinhavada às metas e aos objetivos estratégicos da organização. Pode, inclusive, caracterizar a ritualização da própria estratégia.

Alguns dados da pesquisa realizada pela Associação Brasileira de Treinamento e Desenvolvimento (ABTD), denominada O Retrato do Treinamento no Brasil 2006/2007, mostram o cenário dos programas de desenvolvimento organizacional no país (Tabela 1 ).

Como se pode constatar por meio da Tabela 1 , o número de horas anuais de treinamento por funcionário no Brasil é de 47 horas, o equivalente a 5,8 dias de trabalho anual, se for considerada uma jornada padrão de 8 horas diárias. Em média, 18\% das organizações estudadas chegam a 80 horas de desenvolvimento anual por funcionário. Essa pesquisa menciona um estudo internacional realizado pela ASTD (American Society for Training and Development) no mesmo período, que analisou um grupo seleto de organizações distribuídas pelo mundo, denominado "grupo líder em desenvolvimento de pessoas". De acordo com esse estudo, essas empresas dedicam, em média, 38 horas anuais de treinamento por pessoa, portanto, 19,15\% abaixo da média brasileira.

Os programas de treinamento e desenvolvimento são primordiais para que as pessoas adquiram conhecimentos, habilidades e atitudes e também para que não se dissociem das mutações do mundo a sua volta. É o que afirma Aquino (1992). A maioria dos autores que aborda o tema considera que o treinamento e o desenvolvimento são compostos pelos seguintes subsistemas: análise de necessidade, planejamento, e execução dos programas e avaliação (ARAÚJO, 2005). Conforme definido anterior- mente, o foco dessa pesquisa é o subsistema de avaliação de treinamento e desenvolvimento.

\section{Avaliação de treinamento e desenvolvimento}

Para Castro (2005), os processos de avaliação e validação dos programas de treinamento e desenvolvimento constituem-se em ferramenta de tomada de decisão estratégica para a alta gerência da organização. O autor afirma que a organização deve procurar reter não apenas os melhores profissionais, mas também o conhecimento que eles possuem de sua longa experiência comportamental e conceitual. Além de mensurar a efetividade do próprio programa, o sistema de avaliação promove um aprimoramento contínuo, fornecendo informações para melhorar cada vez mais os estágios dos programas de treinamento e desenvolvimento.

Milioni (2004) afirma que é impossível abordar o tema de avaliação de resultados de treinamento sem que se vincule a essa questão o estabelecimento de objetivos e indicadores. De acordo com o autor, indicadores são partículas dos objetivos e sua elaboração é simplificada na medida em que se sabe exatamente onde chegar com a deflagração de um programa de desenvolvimento.

Os indicadores não podem estar desvinculados de objetivos maiores, como aqueles relacionados à estratégia da organização. É o que afirma Milioni (2005), que definiu 118 indicadores da gestão de treinamento e desenvolvimento e os classificou em diversos campos, como os indicadores aplicáveis ao processo de treinamento na área comercial. Nesse campo, estão o número de visitas efetuadas, o aumento das vendas, o número de contratos fechados, os resultados obtidos em relação às metas, os índices de preços e descontos, o incremento da carteira de clientes, a pontualidade na entrega de produtos e os percentuais de negócios fechados.

Castro (2005), Palmeira (2004) e Araújo (2005) são unânimes em considerar que os estudos de Kirkpatrick (1975) são fundamentais para a compreensão dos níveis

\section{Tabela 1 - Comparação entre Indicadores de T\&D no Brasil e em outras regiões do mundo}

\begin{tabular}{|l|c|c|c|c|c|}
\hline \multicolumn{1}{|c|}{ DADO } & BRASIL & EUA & ÁSIA & $\begin{array}{c}\text { EUROPA } \\
\text { AMÉRICA } \\
\text { LATINA }\end{array}$ \\
\hline $\begin{array}{l}\text { Número médio de horas anuais de treinamento } \\
\text { por funcionário }\end{array}$ & 47 & 30 & 30 & 36 & 31 \\
\hline $\begin{array}{l}\text { Percentual de investimento anual em treinamento } \\
\text { em relação à folha de pagamento }\end{array}$ & 3,2 & 2,2 & 3,7 & 2,5 & 2,5 \\
\hline
\end{tabular}

Fonte: Adaptado da ABTD (2006). 
de avaliação de programas de treinamento e desenvolvimento. Esse autor indica quatro níveis de avaliação, apresentados no Quadro 1.

Phillips (1997 apud PALMEIRA, 2004) sugere uma modificação da escala de avaliação de Kirkpatrick: adicionar um quinto nível relacionado ao retorno sobre o investimento (ROI). É possível, segundo esse autor, converter os dados do nível 4 em valores monetários, isolando-os e comparando os benefícios obtidos com o programa de desenvolvimento aos seus custos.

Castro (2005) resume o ROI como os custos subtraídos dos benefícios totais para se gerar o valor do benefício líquido, o qual é dividido pelos custos. Afirma que é necessário ir além do ROI. Para isso, sugere, além dessa ferramenta de avaliação de programas de desenvolvimento de pessoas, outras duas. A primeira é o Human Performance Improvement (HPI), que é um conjunto de técnicas e conceitos que devem ser aplicados em determinado ambiente organizacional para identificar necessidade ou problema de desempenho, diagnosticar uma ou mais causas principais dessa necessidade e propor a melhor intervenção para resolver o problema, ampliando a performance de determinada pessoa ou grupo de trabalho.

A segunda ferramenta sugerida por Castro (2005) para avaliação de programas de desenvolvimento de pessoas é o Balanced Scorecard (BSC), com suas quatro perspectivas: dos clientes, dos processos internos, de inovação e aprendizagem e financeira. $\mathrm{O}$ autor sugere uma combinação desses métodos para maior eficácia na avaliação dos programas de desenvolvimento.

Outro aspecto relevante no que diz respeito à avaliação de impactos de programas de desenvolvimento é a necessidade de isolamento da variável. Uma questão bastante proeminente que permeia a análise dos pro- gramas de desenvolvimento é: como isolar os efeitos do treinamento? Na visão de Palmeira (2004), como em química, nas condições normais de temperatura e pressão (CNTP), se nada adicional aconteceu nas condições do ambiente e do mercado, o treinamento é responsável. Se outras variáveis influíram, o treinamento pode ter colaborado com outras práticas. Por vezes, é possível, inclusive, estimar um percentual a ser atribuído ao treinamento. Entretanto, nem tudo poderá ser traduzido em números. A autora considera que o que não puder ser calculado deve ser convertido em benefício intangível. É o caso de aspectos como melhorias no relacionamento, na cooperação, na comunicação e outros que, comumente, se caracterizam como objetivos de programas de desenvolvimento comportamental.

\section{Programas de desenvolvimento comportamental para equipes de área comercial}

De acordo com Galvão (2006), desenvolvimento comportamental é um processo de reflexão e ação. Jogos, vivências, treinamentos ao ar livre (outdoor training), técnicas de meditação e relaxamento, teatro, musicoterapia, vídeos, entre outros recursos, métodos e técnicas de desenvolvimento comportamental são utilizados pelas empresas para otimizar a efetivação dos objetivos estratégicos.

Ao promover programas de desenvolvimento e incentivos para o trabalho em equipe, para a motivação e para a melhoria das relações no trabalho, as organizações clarificam a premissa de conciliar produtividade e bons resultados com qualidade de vida e desenvolvimento dos seus colaboradores. Os programas promovidos pelas organizações que apresentam essas características visam a desenvolver competências comportamentais que levem os indivíduos, os grupos e as organizações ao desenvolvimento e à conquista dos objetivos.

\section{Quadro 1 - Escala dos níveis de avaliação de Kirkpatrick}

\begin{tabular}{|l|l|l|}
\hline Nivel 1 & Avaliação de reação & Avalia se os participantes gostaram do programa de treinamento. \\
\hline Nível 2 & Aprendizagem & $\begin{array}{l}\text { Observa o conhecimento adquirido pelos participantes ao final do treinamento, } \\
\text { o que eles sabem a mais em relação ao que não sabiam antes. }\end{array}$ \\
\hline Nível 3 & Mudança de comportamento & $\begin{array}{l}\text { Avalia o que há de diferente no comportamento dos participantes após as } \\
\text { intervenções do treinamento. }\end{array}$ \\
\hline Nivel 4 & Resultados & $\begin{array}{l}\text { Avalia o impacto gerado na organização a partir das mudanças de comportamento } \\
\text { ocorridas após a realização do treinamento. }\end{array}$ \\
\hline
\end{tabular}

Fonte: Adaptado de Palmeira (2004) e Castro (2005). 
Comumente, as pessoas associam programas de desenvolvimento comportamental com motivação, psicologismos, emoções e catarses. Segundo Galvão (2006), isso ocorre porque existe a suposição de que o processo cognitivo está dissociado do comportamental. É importante ressaltar que aprender um comportamento não pode estar desvinculado da vida das pessoas. Não se pode pedir que as pessoas esqueçam o que são para experimentar novos comportamentos sem correr riscos. Não se pode separar a mudança de quem muda, afirma Galvão (2006). O autor postula que os programas de desenvolvimento comportamental propõem, em princípio, a experiência de entender ou justificar o que ocorre dentro do indivíduo e o impacto deste sobre o coletivo, o que levará a uma compreensão melhor do outro.

Direcionados para equipes de área comercial, os programas de desenvolvimento comportamental podem contribuir para a consolidação de uma cultura orientada ao mercado e ao cliente. Numa organização orientada para a estratégia e numa estratégia orientada para o cliente e para o mercado, a área de marketing e vendas acaba por assumir um papel determinante na conquista de vantagem competitiva.

Conforme Narver, Slater e Tietje (1998), orientação para o mercado é uma cultura em que todos se encontram comprometidos com a criação contínua de um valor superior ao cliente. Todos os indivíduos e funções podem e devem contribuir com essa criação.

Uma organização que pretende orientar-se para o mercado precisa ajustar seus recursos para este fim. Na visão de Day (2001), precisa viver continuamente com os clientes para conhecer os detalhes das experiências e dos problemas destes no contexto de comprar e usar.

Kotler (1998), por sua vez, afirma que os objetivos da força de vendas são mais amplos do que, simplesmente, vender. Devem, também, mostrar aos clientes potenciais como sua empresa pode ajudá-los a melhorar a rentabilidade. Independente do contexto da venda, os vendedores desempenham uma ou mais das seguintes funções: prospecção, definição de alvo, comunicação, venda, serviço, coleta de informações e alocação de produtos.

O marketing de relacionamento, cada vez mais valorizado, exige da força de vendas o desenvolvimento de competências que extrapolam o processo da venda em si. De acordo com Rust, Zeithaml e Lemon (2001), o mundo dos negócios está se organizando em torno do cliente. Essa forma de gestão visa a gerenciar por meio do valor do cliente, mais do que do valor da marca. O foco precisa estar na lucratividade do cliente. Os programas de desenvolvimento para equipes de marketing e vendas devem con- templar o aprimoramento de habilidades para essa visão.

A cultura de orientação para o mercado se caracteriza como grande força no relacionamento com o cliente, podendo otimizar estratégias que contemplem a fidelização como ação competitiva. No entanto, essa estratégia requer uma nova forma de pensar e de fazer negócios: para conquistar a fidelidade do cliente é fundamental que empresas competitivas contemplem a fidelidade ao cliente como um importante valor cultural.

As pessoas da área Comercial precisam desenvolver competências para assimilar essa cultura e disseminá-la aos demais grupos da organização. Os programas de desenvolvimento comportamental podem ser de grande contribuição para que essa condição se efetive. Asnis (2006) lembra que os programas de desenvolvimento para vendas, na maior parte das vezes, buscam uma mudança de atitude de seus participantes. Nos casos em que o foco é o comportamento, a autora considera que atividades vivenciais são mais eficazes.

No entanto, quaisquer que sejam os métodos e os formatos dos programas de desenvolvimento comportamental aplicados em equipes de área comercial, eles devem capacitar as pessoas para a consolidação dos objetivos estratégicos da organização.

\section{METODOLOGIA}

Com o objetivo de identificar e analisar a relação entre o investimento em programas de desenvolvimento comportamental aplicados em equipe de área comercial e os resultados obtidos em relação aos objetivos estratégicos de uma organização do setor de comunicação de Curitiba a Rede Independência de Comunicação (RIC), esta pesquisa se baseou na seguinte hipótese: os resultados obtidos em relação aos objetivos estratégicos da organização variam de acordo com o investimento em programas de desenvolvimento comportamental aplicados em equipe de área comercial. A partir dessa hipótese, foram testadas 19 hipóteses relacionadas com os objetivos estratégicos da organização, que estão listadas no Quadro 2.

Essa investigação de natureza quantitativa possui caráter exploratório e perspectiva longitudinal, pois foram analisados os investimentos em programas de desenvolvimento comportamental e os resultados em relação aos objetivos estratégicos no período compreendido entre os meses de maio e dezembro de 2006. A população investigada é constituída pelos integrantes da área comercial da RIC e a amostra é composta pela equipe de área comercial responsável pelas vendas ao varejo na 
região de Curitiba. Utilizou-se, portanto, uma amostra não probabilística.

A escolha de uma organização do segmento de comunicação deu-se em função de dois fatores principais: (1) a importância da imprensa no contexto social e político nacional; (2) o fato de as empresas de serviços e, em especial, de comunicação, terem se firmado como grandes usuárias de programas de treinamento e desenvolvimento comportamental, conforme pesquisa da ABTD (2006) citada anteriormente. A seleção da equipe responsável pelas vendas ao varejo na região de Curitiba aconteceu por ser ela a responsável por uma fatia importante do faturamento da empresa. Além disso, a totalidade dos componentes dessa unidade submeteu-se a todos os programas de desenvolvimento comportamental promovidos pela organização no período estudado. Essa equipe é composta por cinco executivos de contas, coordenados por dois supervisores de vendas. Esta e outras equipes de varejo são gerenciadas por um diretor comercial. Toda a área de marketing e vendas é dirigida pelo diretor de mercado e planejamento.

Tendo como subsídio a pesquisa teórica, foram identificados, numa primeira fase, os objetivos estratégicos e seus indicadores baseados no BSC (KAPLAN; NORTON, 2004; CASTRO, 2005). Esses objetivos estratégicos foram submetidos, por escrito, à apreciação do diretor de mercado e planejamento, considerado o maior estrategista da organização para os propósitos desta pesquisa. Considerando a estratégia da empresa, esse estrategista redefiniu os objetivos. Excluiu alguns, modificou outros e incluiu mais alguns. O resultado dessa validação permitiu eleger 19 objetivos estratégicos que embasaram a formulação das hipóteses. A intenção dessa validação foi, portanto, que os objetivos analisados estivessem de acordo com a realidade da empresa.

Após a definição dos objetivos estratégicos, procedeu-se à coleta dos dados relativos aos investimentos em programas de desenvolvimento comportamental e aos resultados obtidos em relação aos objetivos estratégicos. Esses dados foram obtidos a partir da investigação dos seguintes documentos: relatórios semanais de visitas aos clientes de cada executivo de venda e de cada supervisor da área estudada no período compreendido entre 01 de maio a 31 de dezembro de 2006; planilhas mensais com resumo do desempenho da área de varejo; relatórios de previsão de vendas; relatórios gerenciais; relatórios de audiência; listas de preços; portfólio de produtos de vendas; planilhas financeiras da área comercial.

O tratamento dos dados envolveu técnicas estatísticas de análise de regressão linear simples e análise uni- variada (estatísticas descritivas). O programa utilizado para o tratamento dos dados foi o software estatístico XLSTAT da Microsoft, versão 7.5. Os dados receberam tratamento estatístico descritivo. Como os dados variavam em função do investimento em programas de desenvolvimento comportamental, do desempenho e dos resultados da equipe foi utilizada para seu tratamento a análise de regressão linear simples. Também foi analisado o teste $t$-student para avaliar a significância dos parâmetros estimados.

\section{CARACTERIZAÇÃO DO ESTUDO DE CASO}

A Rede Independência de Comunicação (RIC) é afiliada da Rede Record de Televisão e da Rádio Jovem Pan. Possui quatro canais de TV, três rádios FM e dois portais na internet. Inaugurada em 1985, conta, atualmente, com 224 funcionários, sendo 69 apenas na área Comercial. De acordo com o planejamento estratégico da empresa, a RIC tem a seguinte missão do negócio: "um cliente RIC deve ter uma experiência de qualidade e ficar encantado com as soluções em mídia propostas pela empresa, obtendo resultados dimensionados e projetados ao tamanho RIC, bem como atendendo as expectativas dos seus valores de compra".

Os valores da empresa denotam alguns aspectos importantes da sua cultura: a orientação para o mercado, conciliada com uma estratégia baseada na capacitação, no conhecimento e na tecnologia, recursos internos à organização. A área de Marketing da RIC estabelece seus objetivos estratégicos anualmente. De março de um ano até fevereiro do ano seguinte, a empresa define os pilares que constituem suas metas. Esses objetivos, segundo a direção da empresa, podem ser resumidos em três grandes pilares:

a) uma relação eficaz entre orçamento e custo: de onde foi extraída a "meta de orçamento" que é a referência do patamar de equilíbrio financeiro da empresa;

b) um crescimento das vendas: de onde foi extraída a "meta de venda", base para a premiação individual;

c) atingir a meta de participação de mercado, que é a referência do potencial de venda no mercado.

Os 19 objetivos contemplados nesta pesquisa advêm também desses pilares. São, de certa forma, um desdobramento dos objetivos citados acima.

A equipe pesquisada, composta por cinco executivos de contas e dois supervisores de vendas, foi contratada no início do mês de maio de 2006, período que marca, 
também, o início desta investigação. Composta por pessoas jovens, a maioria não contava com experiência profissional na área comercial em televisão e alguns, inclusive, nem em outro segmento de comunicação antes da contratação. A exceção é o diretor da área, que já trabalha na empresa há dez anos. Diante disso, é possível inferir que a atuação profissional e os resultados conquistados pela equipe advieram da capacitação que receberam nos programas de desenvolvimento, que contaram com a atuação dos gestores da área e de ações promovidas pelo RH da organização.

\section{APRESENTAÇÃO E ANÁLISE DOS RESULTADOS}

A apresentação dos resultados obtidos na pesquisa de campo está estruturada em duas seções: análise descritiva dos dados e análise confirmatória das hipóteses formuladas.

\section{Análise descritiva}

No período estudado (maio a dezembro de 2006), a empresa promoveu 232 horas de desenvolvimento e capacitação para a equipe pesquisada, muitas delas em conjunto com a área Comercial, o que aponta para uma média mensal de 29 horas. Foram 15 programas de desenvolvimento comportamental, distribuídos em um total de 40 encontros para a equipe de varejo. Os valores dos investimentos considerados nesse caso incluíram, além dos custos com consultorias, instrutores, transporte, alimentação e hospedagem e outros que viabilizaram a execução dos programas, o valor do salário de cada participante proporcionalmente ao tempo de execução.
Os valores investidos mensal e cumulativamente são apresentados na Tabela 2.

Os valores mínimos, correntes nos meses de maio a julho, indicam a utilização exclusiva de recursos internos incidindo sobre os custos dos programas. Já nos três meses seguintes, os investimentos aumentaram sobremaneira em função de que incluíram os custos de contratações de empresas de consultoria e também de hotéis ou pousadas onde os programas foram executados.

Alguns dos objetivos estratégicos da organização estão alicerçados nos resultados financeiros obtidos pela amostra. A base dos indicadores para esses objetivos foi o faturamento da equipe estudada, que teve grande variação de crescimento no período. A variação foi positiva na maioria dos meses analisados. No total, essa oscilação no faturamento foi de $83,17 \%$. A média mensal do crescimento no período foi de $9,03 \%$, demonstrando grande evolução no desempenho da equipe.

O faturamento decorrente dos resultados das vendas efetivadas pela equipe estudada aumentou progressivamente. A justificativa da oscilação negativa no mês de junho pode estar num evento esportivo. A copa do mundo pode ter sido a responsável pela retração do mercado no período, pois os anunciantes desse evento são, em grande parte, do mercado nacional e não regional. Isso mostra a importância da influência do cenário externo na definição dos objetivos e metas dessa organização.

Outro resultado a ser analisado é o desempenho em relação às metas de vendas idealizadas pela organização. Conforme declarado anteriormente, as metas de vendas são um dos pilares que alicerçam os objetivos estratégicos da empresa. Elevadas, buscam a superação dos limites

Tabela 2 - Investimentos em programas de desenvolvimento comportamental em equipe de área comercial (maio a dezembro de 2006).

\begin{tabular}{|l|c|c|}
\hline \multicolumn{1}{|c|}{ MÊS } & $\begin{array}{c}\text { VALOR INVESTIDO } \\
\text { MENSAL EM R\$ }\end{array}$ & $\begin{array}{c}\text { VALOR INVESTIDO } \\
\text { ACUMULADO EM R\$ }\end{array}$ \\
\hline Maio & $2.115,75$ & $2.115,75$ \\
\hline Junho & 488,25 & $2.604,00$ \\
\hline Julho & 610,31 & $3.214,31$ \\
\hline Agosto & $91.464,75$ & $94.679,06$ \\
\hline Setembro & $34.464,75$ & $129.143,81$ \\
\hline Outubro & $86.668,19$ & $215.812,00$ \\
\hline Novembro & $11.813,75$ & $227.625,75$ \\
\hline Dezembro & $11.813,75$ & $239.439,50$ \\
\hline
\end{tabular}

Fonte: Planilhas da área comercial e RH. 
da equipe e a lucratividade. As metas definem as ações de venda e a política de premiações para executivos e supervisores que se destacam em suas performances e conseguem superá-las. Servem como um indicador fundamental para o levantamento das necessidades de desenvolvimento técnico e comportamental dos executivos de contas.

Houve uma grande evolução dos resultados obtidos na segunda metade do período analisado em relação aos primeiros quatro meses. Superou os $70 \%$ na maioria dos oito meses do estudo, chegando a atingir $92,63 \%$ em outubro. A média desse indicador é de $72,91 \%$ no período analisado. É importante ressaltar que as metas de vendas estipuladas pela empresa também aumentaram. A melhora do desempenho da equipe nesse período não está, portanto, relacionada a um menor ou igual grau de exigência da organização. Isso demonstra que a equipe correspondeu à elevação das expectativas da empresa.

Além do desempenho em relação às metas de vendas, o faturamento é a base para outros objetivos estratégicos da organização. Entre eles está o "faturamento em relação à meta de orçamento". A diferença desse objetivo em relação àquele é que a meta do orçamento é menos elevada e esta serve como referência para o patamar de equilíbrio da organização. Sobre ela é que se estipulam o orçamento e toda a política de investimentos. Nos meses de outubro e novembro, os resultados da equipe superaram a meta de orçamento. A média dos índices obtidos em relação a esse indicador no período estudado foi de $89 \%$.

A meta em relação à participação de mercado é a meta de referência do potencial de venda no mercado, definida da seguinte maneira: a "meta share" pode ser vista como "o tamanho de faturamento que o mercado permite que a empresa alcance". É um indicador estratégico que busca a conquista da participação de mercado conforme a participação da programação comercializada. Os resultados obtidos pela equipe em relação a esse índice também foram crescentes no período estudado.

Outro objetivo que apresenta o faturamento como determinante do seu indicador é o desempenho em vendas em relação ao mesmo período do ano anterior. Apenas no mês de junho o ano de 2006 teve menor faturamento em comparação com o mesmo período de 2005, provavelmente em decorrência da copa do mundo, conforme descrito anteriormente. Houve grandes variações nesses índices. A amplitude da amostra foi maior que 90 , o que significa que esta foi a diferença entre outubro, o mês de maior aumento, e junho, quando houve recuo. A média mensal de crescimento do faturamento de 2006 em relação ao ano anterior no período analisado foi de $20,5 \%$.
Em comparação com o faturamento global da empresa, a área analisada vem, mês a mês, melhorando sua participação. Esse indicador considera exclusivamente as vendas para clientes do mercado de mídia de TV.

O desempenho em vendas da equipe analisada também compõe o indicador do objetivo faturamento sobre as vendas para clientes estratégicos e influenciadores.

É importante reiterar que a base dos objetivos estratégicos da empresa é a orientação para o mercado e para o cliente. Sendo o cliente o foco de toda mobilização estratégica da organização, seria contra-senso considerar apenas as agências de publicidade e propaganda como estratégicas. Esses clientes deveriam ser considerados influenciadores, já que influenciam outros clientes a anunciarem na RIC. RICTV. No entanto, é evidente o destaque que adquirem quando se analisam as ações estratégicas da empresa e a disponibilização dos recursos internos para sua efetivação. Os negócios fechados com as agências são decorrentes de ações de vendas dos supervisores da equipe estudada, enquanto os clientes dessas agências são visitados pelos executivos de contas.

Novamente se percebe que junho foi o mês onde houve resultado menos expressivo. De julho a novembro, o crescimento nos resultados de vendas para clientes estratégicos foi constante. O melhor desempenho da equipe foi em novembro, responsável por $17 \%$ das vendas da amostra no período analisado. A diferença entre o pior e o melhor resultado (respectivamente, junho e novembro) foi de 54\%.

Os bons resultados apresentados pela amostra em relação ao desempenho financeiro relativo ao faturamento não se reproduziu na análise dos indicadores relativos aos descontos oferecidos pela equipe ao mercado, que são: desconto financeiro oferecido ao mercado anunciante; desconto oferecido aos clientes estratégicos; desconto financeiro em relação à meta de desconto. Todos esses indicadores analisados tiveram seus resultados abaixo da expectativa definida pela empresa em seu plano estratégico.

Além das questões pertinentes ao desempenho financeiro nas vendas, esta pesquisa analisou também indicadores da própria relação com os clientes e com o mercado. A média mensal de clientes que anunciaram na RIC em 2005 e 2006 é muito próxima. Em 2006 ficou em 32 e em 2005 havia ficado em 31. Esses números mostram que a equipe analisada, que foi contratada em maio de 2006 , conseguiu resultados adicionais à equipe anterior, já que o faturamento decorrente das vendas ao mercado anunciante em 2006 teve um crescimento de mais de 16\% em relação ao mesmo período do ano anterior, mesmo com números tão próximos de clientes. 
Nesse sentido, um objetivo que merece destaque é a diminuição da evasão dos anunciantes que, ao lado da fidelização do cliente, se constitui em ponto importante da estratégia da organização. Em ambos os indicadores, o melhor resultado obtido aconteceu em novembro, o que poderia aparentar uma forte relação entre eles. No entanto, a correlação entre esses dois indicadores é de apenas $40 \%$. Não muito significativa, portanto. É possível analisar que, nos primeiros cinco meses do estudo, os índices de redução da evasão foram negativos, ou seja, houve um número significativo de clientes que deixaram de anunciar na empresa em comparação ao mesmo período do ano anterior. No entanto, nos meses de outubro a dezembro, a melhora foi significativa. Por isso, o índice de redução de evasão de clientes em todo o período estudado foi positivo.

O número de clientes que mostraram fidelidade à empresa também foi maior na segunda metade do período pesquisado, compreendido entre setembro e dezembro. Estes também foram os meses em que houve maior investimento em programas de desenvolvimento comportamental aplicados na equipe.

Outro objetivo estratégico importante no que diz respeito à relação com o mercado é o número de visitas aos clientes. Este número teve seu ápice no mês de agosto. No entanto, a produtividade da equipe foi baixa neste mês, não passando de $3,7 \%$. Geralmente, o número de visitas de cada executivo é proporcional ao número de dias úteis do período. Meses que contam com feriados, convenções de vendas, treinamentos ou reuniões acabam comprometendo negativamente os índices. Essa avaliação, no entanto, não serve para explicar a produtividade. Dezembro, por exemplo, foi o mês com o menor número de dias trabalhados na área comercial. Conseqüentemente, foi quando houve o menor número de visitas aos clientes. No entanto, foi exatamente neste mês que houve a maior produtividade da equipe. De cada 100 visitas, mais de 8 contratos foram fechados.

\section{Análise confirmatória das hipóteses formuladas}

A análise da relação entre os programas de desenvolvimento comportamental e os objetivos estratégicos da empresa permite chegar ao cerne desta pesquisa com a confirmação ou não das hipóteses formuladas e que embasaram a investigação. A Figura 1 apresenta o modelo utilizado para analisar a relação entre as variáveis e seus resultados.

Existe relação entre o investimento e a maioria dos objetivos estratégicos da empresa. A análise dos resultados referentes aos testes das hipóteses corrobora essa afirma- ção. A conclusão da análise confirmatória das Hipóteses está resumida no Quadro 2.

A relação entre os investimentos em programas de desenvolvimento comportamental e os objetivos estratégicos da organização foi significativa na maioria dos objetivos estudados, traduzidos em cada uma das hipóteses testadas. Isso permite concluir que, de modo geral, a efetivação dos objetivos estratégicos da empresa estudada varia em função de investimentos em programas de desenvolvimento comportamental.

Das relações investigadas a partir das hipóteses elaboradas, algumas merecem destaque. É o caso da relação entre os investimentos em desenvolvimento comportamental e os seguintes objetivos: o desempenho financeiro (H1); o número de clientes que anunciam na empresa (H2); o faturamento em relação às metas de vendas, de orçamento e de share (H4, H11, H18); o desempenho para clientes estratégicos e influenciadores (H6); o número de contratos fechados (H9); a porcentagem de usuários em relação à carteira de clientes (H15); a produtividade na relação com o cliente (H17); a participação do desempenho da equipe nos resultados globais da empresa (H19). O investimento em programas de desenvolvimento comportamental foi capaz de explicar mais de $70 \%$ da variabilidade de todos esses objetivos.

O coeficiente de explicação $\left(R^{2}\right)$ mostra que a variação dos investimentos em programas de desenvolvimento comportamental não é capaz de explicar as variações na média de descontos fornecidos ao mercado anunciante, aos clientes estratégicos e influenciadores e à meta de descontos estipulada pela organização (H7, H8, H12). Esse resultado se deve, provavelmente, ao fato de que não houve, no período estudado, nenhuma ação de desenvolvimento que focalizasse a política de preços da organização. Nem mesmo os conteúdos que abordaram técnicas de vendas ou negociação enfatizaram a questão dos descontos. Essa conclusão subsidiou a inclusão desses temas nas ações que constam no planejamento de desenvolvimento de pessoas para 2007.

\section{CONSIDERAÇÕES FINAIS}

A organização estudada faz grandes investimentos em programas de desenvolvimento comportamental para suas equipes de vendas. A estratégia da empresa, centrada na relação com o mercado e com o cliente, enfatiza as ações relativas ao desenvolvimento das pessoas.

A pesquisa teórica sobre esse tema possibilitou a constatação da importância do alinhamento entre as pessoas, 
Figura 1 - Modelo utilizado para análise das hipóteses e seus resultados

\begin{tabular}{|c|c|c|c|c|}
\hline & & $\mathrm{H} 1:(+)$ & & Objetivo 1 \\
\hline & $B=0,598$ & significativo & $\mathrm{R} 2=95,63 \%$ & \\
\hline & & $\mathrm{H} 2:(+)$ & & Objetivo 2 \\
\hline & $B=0,714$ & significativo & $\mathrm{R} 2=85,72 \%$ & \\
\hline & & H3: $(+)$ & & Objetivo 3 \\
\hline & $B=0,066$ & significativo & $\mathrm{R} 2=62,12 \%$ & \\
\hline & & $\mathrm{H} 4:(+)$ & & Objetivo 4 \\
\hline & $B=0,284$ & significativo & $\mathrm{R} 2=81,72 \%$ & \\
\hline & & H5: $(+)$ & & Objetivo 5 \\
\hline & $B=0,440$ & significativo & $\mathrm{R} 2=54,60 \%$ & \\
\hline & & $\mathrm{H} 6:(+)$ & & Objetivo 6 \\
\hline & $B=0,409$ & significativo & $\mathrm{R} 2=83,12 \%$ & \\
\hline & & H7: (-) & & Objetivo 7 \\
\hline & $B=0,001$ & não significativo & $\mathrm{R} 2=3,53 \%$ & \\
\hline & & H8: (-) & & Objetivo 8 \\
\hline & $B=0,014$ & não significativo & $\mathrm{R} 2=26,68 \%$ & \\
\hline $\begin{array}{l}\text { Investimento em } \\
\text { Programa de }\end{array}$ & & $\mathrm{Hg} \cdot(+)$ & & Objetivo 9 \\
\hline Desenvolvimento & $B=0,232$ & significativo & $\mathrm{R} 2=91,54 \%$ & \\
\hline Comportamental & & & & \\
\hline & & H10: $(+)$ & & Objetivo 10 \\
\hline & $B=0,012$ & não significativo & $\mathrm{R} 2=22,85 \%$ & \\
\hline & & H11: $(+)$ & & Objetivo 11 \\
\hline & $B=0,337$ & significativo & $\mathrm{R} 2=81,68 \%$ & \\
\hline & & H12: $(-)$ & & Objetivo 12 \\
\hline & $B=-0,001$ & não significativo & $\mathrm{R} 2=3,53 \%$ & \\
\hline & & H13: $(+)$ & & Objetivo 13 \\
\hline & $B=0,026$ & não significativo & $\mathrm{R} 2=8,75 \%$ & \\
\hline & & $\mathrm{H} 14:(+)$ & & Objetivo 14 \\
\hline & $B=0,187$ & não significativo & $\mathrm{R} 2=18,23 \%$ & \\
\hline & & H15: $(+)$ & & Objetivo 15 \\
\hline & $B=0,096$ & significativo & $\mathrm{R} 2=95,18 \%$ & \\
\hline & & H16: $(+)$ & & Objetivo 16 \\
\hline & $B=-0,793$ & não significativo & $\mathrm{R} 2=16,26 \%$ & \\
\hline & & $\mathrm{H} 17:(+)$ & & Objetivo 17 \\
\hline & $B=0,040$ & significativo & $\mathrm{R} 2=84,39 \%$ & \\
\hline & & H18: $(+)$ & & Objetivo 18 \\
\hline & $B=0,165$ & significativo & $\mathrm{R} 2=86,81 \%$ & \\
\hline & & H19: (+) & & Objetivo 19 \\
\hline & $B=0,069$ & significativo & $\mathrm{R} 2=93,93 \%$ & \\
\hline
\end{tabular}


os processos de gestão humana e os objetivos definidos pela estratégia. Na organização investigada, os objetivos estratégicos estão alinhados com a cultura e com os valores da organização. Centrados na relação com o cliente e com o mercado, fundamentam-se em indicadores mensuráveis e passíveis de investigação a partir das ferramentas e dos sistemas inteligentes da própria organização, o que permitiu mapear o investimento em programas de desenvolvimento comportamental em equipe de área Comercial. Acima da média das empresas do Brasil e do mundo, esses investimentos contemplaram ações que, em sua maioria, abordaram conteúdos alinhavados aos objetivos que a organização pretendia atingir.

Os programas de desenvolvimento comportamental encontraram nessa cultura organizacional um terreno fértil para a aplicação dos seus conteúdos. A empresa não só promoveu a sua efetivação como também ofereceu as condições no dia-a-dia para a atuação das pessoas de acordo com os conteúdos desenvolvidos nos programas e para além deles. Nessa realidade, a capacitação e o desenvolvimento das pessoas, mais do que ações que requerem investimentos financeiros, caracterizam-se como valores organizacionais e podem ser considerados, por si só, também um objetivo estratégico.

Esta pesquisa também permite concluir que a equipe estudada apresentou bons resultados no que diz respeito ao desempenho financeiro, exceto na política de preços e descontos. Dentre esses objetivos, destacam-se o número de contratos, que foi crescente no período analisado, assim como o crescimento da participação do desempenho financeiro da equipe nos resultados globais da empresa. Houve, ainda, um resultado satisfatório no que tange ao cumprimento das metas de vendas e daquelas relativas ao orçamento e ao share, importantes indicadores de investimentos e de relação com o mercado e que constituem os pilares estratégicos da empresa. No que diz respeito aos

Quadro 2 - Conclusões da análise confirmatória das hipóteses testadas

\begin{tabular}{|c|c|c|}
\hline $\begin{array}{c}\text { HIPÓTESES } \\
\text { QUANTO MAIOR O INVESTIMENTO EM PROGRAMAS DE } \\
\text { DESENVOLVIMENTO COMPORTAMENTAL [...] }\end{array}$ & EFEITO & SUPORTADA \\
\hline H1: [...] maior o faturamento mensal; & Positivo & Sim \\
\hline H2: [...] maior o número de clientes que anunciam na empresa; & Positivo & Sim \\
\hline H3: [...] maior a fidelidade de clientes; & Positivo & $\operatorname{Sim}$ \\
\hline H4: [...] maior o faturamento em relação à meta de vendas; & Positivo & $\operatorname{Sim}$ \\
\hline H5: [...] maior o faturamento em relação ao mesmo período do ano anterior; & Positivo & $\operatorname{Sim}$ \\
\hline H6: [...] melhor o desempenho em vendas para clientes estratégicos e influenciadores; & Positivo & $\operatorname{Sim}$ \\
\hline H7: [...] menor a média de desconto fornecido ao mercado anunciante; & Negativo & Não \\
\hline H8: [...] menor a média de desconto fornecido aos clientes estratégicos e influenciadores; & Negativo & Não \\
\hline H9: [...] maior o número de contratos fechados; & Positivo & $\operatorname{Sim}$ \\
\hline H10: [...] maior o número de treinamentos realizados; & Positivo & Não \\
\hline H11: [...] maior o desempenho das vendas em relação à meta de orçamento; & Positivo & $\operatorname{Sim}$ \\
\hline H12: [...] menor a média de desconto em relação à meta de desconto idealizada; & Negativo & Não \\
\hline $\begin{array}{l}\text { H13: [...] maior o número de reuniões para discussões de metas estratégicas e do } \\
\text { funcionamento da equipe; }\end{array}$ & Positivo & Não \\
\hline H14: [...] maior o número de clientes usuários; & Positivo & Não \\
\hline H15: [...] maior porcentagem de usuários em relação à carteira de clientes; & Positivo & $\operatorname{Sim}$ \\
\hline H16: [...] maior o número de visitas aos clientes; & Positivo & Não \\
\hline H17: [...] maior a produtividade na relação com o cliente; & Positivo & $\operatorname{Sim}$ \\
\hline H18: [...] maior o resultado obtido em relação ao share; & Positivo & $\operatorname{Sim}$ \\
\hline H19: [...] maior a participação das vendas da equipe no faturamento global; & Positivo & $\operatorname{Sim}$ \\
\hline
\end{tabular}


resultados obtidos na relação com os clientes, a equipe conseguiu diminuir a evasão e aumentar a fidelidade, alcançando produtividade nas visitas ao cliente.

Os resultados desta pesquisa podem estimular as organizações a investirem em programas de desenvolvimento comportamental com o objetivo de maximizar seus resultados. No entanto, a generalização destes resultados é limitada, assim como sua validade externa, por se apoiarem em um estudo em uma única organização do setor de comunicação de Curitiba. Não é possível generalizar os resultados para situações de outras organizações, de outros setores e de outras localidades, posicionando-os mais como reforços teóricos a partir da análise do caso do que como resultados generalizáveis. Ademais, os resultados possuem caráter seminal; não tendo sido aplicadas técnicas de análise de séries de tempo que pudessem eliminar efeitos de correlação entre as repetidas medidas das variáveis dependentes, ou identificar defasagens temporais dos efeitos testados, há oportunidade e interesse para submissão dos dados a testes estatísticos mais sofisticados.

Novos estudos podem revelar com maior amplitude a eficácia das ações de desenvolvimento de pessoas no que diz respeito à melhoria do desempenho e da qualidade de vida dos funcionários, dos resultados da empresa junto ao mercado e ao cliente e dos objetivos estratégicos da organização.

\section{REFERÊNCIAS}

ALLEN, N; MEYER, J. P. Affective, continuance, and normative commitment to the organization: an examination of construct validity. Journal of Vocational Behavior, v. 49, n. 3, p. 252-276, 1996.

ALLEN, N. J; MEYER, J. P. Construct validation in organizational behavior research: the case of organizational commitment. In: GOFFIN R. D.; HELMES E. (Eds) Problems and solutions in human assessment: Honoring Douglas N. Jackson at seventy. Norwell, MA: Kluwer, 2000. p. 285-314.

AQUINO, C. P. Administração de recursos humanos: uma introdução. São Paulo: Atlas, 1992.

ARAÚJO, M. F. Impacto de treinamento e desenvolvimento: uma análise integrada quantitativa e qualitativa. 2005. Tese de Doutorado em Engenharia de Produção, Programa de Pós-Graduação em Engenharia de Produção, Universidade Federal de Santa Catarina, Florianópolis, 2005.

ASNIS, D. M. Treinamento comercial. In: BOOG, G. G; BOOG, M. T. Manual de treinamento e desenvolvimento: processos e operações. São Paulo: Pearson Prentice Hall, 2006.
BARNEY, J. Firm resources and sustained competitive advantage. Journal of Management, 17, n. 1, p. 99-120, 1991

BOXALL, P. F. The strategic HRM debate and the resource-based view of the firm. Human Resource Management Journal, v. 6, n. 3, p. 59-75, 1996.

CAPPELLI, P; SINGH, H. Integrating strategic human resources and strategic management. In: LEWIN, D; MITCHELL, O. S; SHERER, P. D. (Eds) Research frontiers in industrial relations and human resources. Madison, WI: IRRA, 1992. p. 165-192.

CASTRO, A. P. Indo além do ROI em TED. São Paulo: Associação Brasileira de Treinamento e Desenvolvimento, 2005.

COHEN, A. R. MBA: Curso prático de administração: lições dos especialistas das melhores escolas de negócios. Rio de Janeiro: Campus, 1999.

DAY, G. S. A empresa orientada para o mercado: compreender, atrair e manter clientes valiosos. Porto Alegre: Bookman, 2001.

FEUILLETTE, I. RH: o novo perfil do treinador - como preparar, conduzir e avaliar um processo de treinamento. São Paulo: Nobel, 1991. p. 134-135.

GALVÃO, M. O ser humano como ser que aprende: o treinamento comportamental. In: BOOG, G. G; BOOG, M. T. Manual de treinamento e desenvolvimento: gestão e estratégias. São Paulo: Pearson Prentice Hall, 2006.

HUSELID, M. A. The impact of human resource management practices on turnover, productivity, and corporate financial performance. Academy of Management Journal, v. 38, n. 3, p. 635-672, 1995

KANAANE, R; ORTIGOSO, S. A. F. Manual de treinamento e desenvolvimento do potencial humano. São Paulo: Atlas, 2001.

KAPLAN, R. S; NORTON, D. P. Kaplan e Norton na prática. Rio de Janeiro: Elsevier, 2004

KOTLER, P. Administração de marketing: análise, planejamento, implementação e controle. São Paulo: Atlas, 1998.

LADO, A. A; WILSON, M. C. Human resource systems and sustained competitive advantage: a competency-based perspective. Academy of Management Review, v. 19, n. 4, p. 699-727, 1994.

LEPAK, D. P; SNELL, S. A. The human resource architecture: toward a theory of human capital allocation and development. Academy of Management Review, v. 24, n. 1, p. 31-48, 1999.

MILIONI, B. Gestão de treinamento por resultados. São Paulo: Associação Brasileira de Treinamento e Desenvolvimento, 2004. 
MOGGI, J. Estratégias e aspectos globais de T\&D. In: BOOG, G. G.; BOOG, M. T. Manual de treinamento e desenvolvimento: gestão e estratégias. São Paulo: Pearson Prentice Hall, 2006.

NARVER, J. C; SLATER, S. F; TIETJE, B. Creating a market orientation. Journal of Market-Focused Management, v. 2, n. 3, p. 241-255, 1998.

PACHECO, L. et al. Capacitação e desenvolvimento de pessoas. Rio de Janeiro: FGV, 2005.

PALMEIRA, C. G. ROI de treinamento: dicas de como mensurar o resultado financeiro das suas ações de treinamento. Rio de Janeiro: Qualitymark, 2004.

PASCHINI, S. Estrhatégia: alinhando cultura organizacional e estratégia de recursos humanos à estratégia do negócio: a contribuição efetiva de recursos humanos para a competitividade do negócio. Rio de Janeiro: QualityMark, 2006.

REGO, A; CUNHA, M. P; SOUTO, S. Espiritualidade nas organizações e comprometimento organizacional, RAE-eletrônica, v. 6, n. 2, 2007. Disponível em: http://www.rae.com.br/eletronica/index.cfm?FuseAction=A rtigo $\& I D=3840 \& S e c a 0=A R T I G O S \&$ Volume $=6 \&$ Numero $=2 \& A n o=2007$. Acesso em 03.11. 2007.
RICHARD, O. C. Racial diversity, business strategy, and firm performance: a resource-based view. Academy of Management Journal, v. 43, n. 2, p. 164-177, 2001.

ROCHA-PINTO, S. R. et al. Dimensões funcionais da gestão de pessoas. Rio de Janeiro: FGV, 2003.

RUST, R. T; ZEITHAML, V. A; LEMON, K. N. O valor do cliente: o modelo que está reformulando a estratégia corporativa. Porto Alegre: Bookman, 2001.

SARAIVA, E. V; CARRIERI, A. P. A construção de estratégias corporativas sob a perspectiva não determinística. RAE-eletrônica, v. 6, n. 2 , 2007. Disponível em: http://www.rae.com.br/eletronica/index.cfm?F useAction $=$ Artigo $\& I D=3406 \&$ Secao $=$ ARTIGOS $\&$ Volume $=6 \&$ Numero $=2 \&$ Ano $=2007$. Acesso em 02.11. 2007.

ULRICH, D; BROCKBANK, W. The HR value proposition. Boston: Harvad Business Review Press, 2005.

WRIGHT, P. M; DUNFORD, B. B; SNELL, S. A. Human resources and the resource based view of the firm. Journal of Management, v. 27, n. 6 , p. 701-721, Nov. 2001. 